\title{
Delivering medium-density infill development through promoting the benefits and limiting background infill
}

Julian Bolleter, Zoe Myers \& Paula Hooper

To cite this article: Julian Bolleter , Zoe Myers \& Paula Hooper (2020): Delivering medium-density infill development through promoting the benefits and limiting background infill, Journal of Urban Design, DOI: 10.1080/13574809.2020.1854610

To link to this article: https://doi.org/10.1080/13574809.2020.1854610 


\title{
Delivering medium-density infill development through promoting the benefits and limiting background infill
}

\author{
Julian Bolleter ${ }^{\mathrm{a}}$, Zoe Myers ${ }^{\mathrm{b}}$ and Paula Hooper ${ }^{\mathrm{a}}$ \\ ${ }^{a}$ Australian Urban Design Research Centre, University of Western Australia, Perth, WA, USA; 'bSchool of \\ Design, Australian Urban Design Research Centre, University of Western Australia, Perth, WA, USA
}

\begin{abstract}
Australian cities rarely meet their targets for infill development and experience a 'missing middle' in terms of urban density. This paper surveys the barriers to medium-density projects on infill sites in the Western Australian city of Perth and subsequently ventures strategies to alleviate these impediments. The findings indicate that the principal barriers to medium-density infill derive from poor quality low-density infill development, which alienates communities and dissipates the impetus developers require to deliver medium-density projects. The paper concludes that spatial planners should improve strategies for promoting the benefits of density, as well as set minimum residential densities, and site areas, for infill development.
\end{abstract}

\section{Introduction}

Cities are increasingly confronted with enormous socio-economic, health and environmental challenges, and rapid urbanization has manifested in endless peripheral development. Moreover, between 2000 and 2015, globally, the expansion of urbanized land overtook urban population growth, leading to 'urban sprawl' (United Nations 2017). To cope with the issues of sprawl, and to deliver 'equitable, efficient and sustainable use of land and natural resources' (United Nations General Assembly 2016, 14) policymakers are striving for urban infill development according to Smart Growth, Sustainable Development, and New Urbanist agendas (Wheeler 2001). Nonetheless, in many cities globally, densification has proven a challenge and urban sprawl has continued to be the dominant mode of development (Wheeler 2001; Arvola and Pennanen 2014; Dittmar, Belzer, and Autler 2004; Bolleter 2017a).

Australian State and territory capital cities have planning policies to achieve urban infill development to safeguard both rural and biodiverse land in the peri-urban zones and minimize infrastructure costs, commuting times, and the concentration of economic and social vulnerabilities on the fringes of Australian cities (Kelly and Donegan 2015). Across the nation, State Government planning policies for the state capital cities, on average, stipulate that $60 \%$ of all new residential development should be infill development (and $40 \%$ greenfield development), yet these cities typically do not meet their targets (Bolleter and Weller 2013; Newton 2010; Randolph 2006). As Dodson explains ' ... despite more than two decades of consolidation policy, across Australia's major cities, there are vast suburban regions of low-density development' $(2010,495)$. Indeed, Australian cities have some of the lowest residential densities in the world (Hurley, Taylor, and Dodson 2017) (Figure 1). 


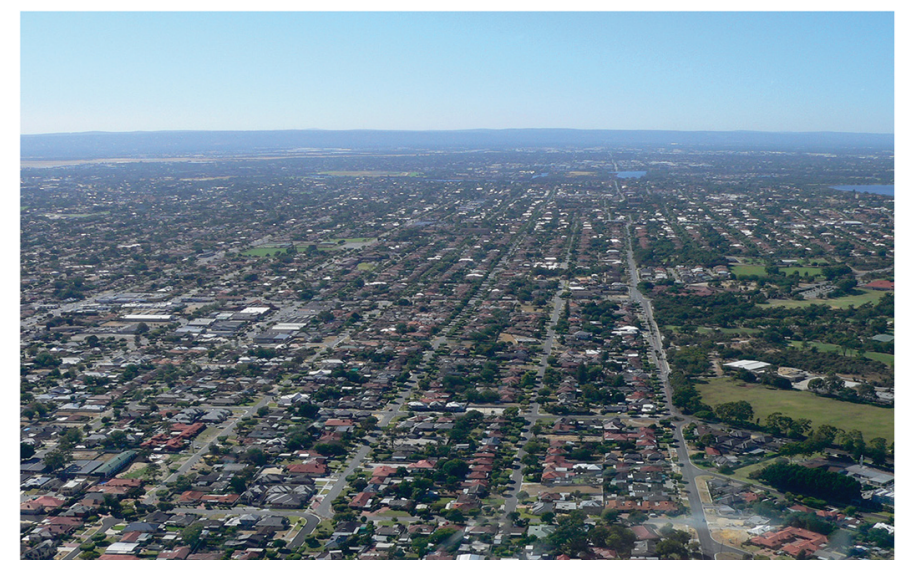

Figure 1. Despite more than two decades of consolidation policy Perth remains predominantly suburban. Image courtesy of Donna Broun and Richard Weller.

Given Australia's population is projected to grow from 25 to 70 million by 2100, Australia's failure to meet its infill targets has serious implications. At a regional scale, the failure of Australian cities to meet their respective infill targets could mean that they grow in what is recognized as a typically unhealthy, socio-economically stratified, unsustainable and unproductive manner (Kelly and Donegan 2015). In response, this paper seeks to understand the major barriers to medium-density infill development in Perth (the capital city of Western Australia), and how these barriers could be mitigated. To allow this, semi-structured interviews were conducted with developers, architects, urban designers, and planners (from government and industry), politicians and community group representatives who are involved in aspects of the planning, design, approval and delivery of medium-density infill.

The paper is structured in the following way. Firstly, the community, regulatory and development feasibility barriers to the delivery of medium-density infill development expressed in the literature are backgrounded. Secondly, the methods are set out. Third, in the results section, the main barriers to the delivery of medium-density infill and related mitigation strategies - as identified by the interviewees - are set out. Fourth, the findings are related to the literature, and the implications of the findings for policy are set out.

\section{Background}

Two divergent forms of redevelopment now characterize many cities in the USA and Australia in particular: high rise, high-density apartments, in areas of high land value; and small scale, low-density infill (Renouf et al. 2020,12) that obviates risk, including that 'presented by design innovations' (Murray 2013). Because of this polarization, commentators recognize that many cities have a 'missing middle.' The 'middle' refers to high-quality medium-density' multi-unit or clustered housing types (Opticos 2018). The literature explains the 'missing middle' by numerous factors, which relate to the community, the regulatory environment, or development feasibility. 


\section{Community barriers}

From North America to Europe and Australia one of the pre-eminent obstacles to mediumdensity infill development is community opposition (Wheeler 2001; Kupke, Rossini, and Stanley 2011, Arvola and Pennanen 2014; Farris 2001; Newton 2010). The literature reasons that community members are repelling medium-density infill in their neighbourhoods for several reasons. Firstly, many residents perceive infill as negatively impacting on their amenity. In particular, they worry infill will degrade their neighbourhood's character and amenity (Maginn and Foley 2017), decrease greenspace (Searle 2004), threaten privacy, block sunlight and views (Arvola and Pennanen 2014) and increase traffic and parking issues (Holling and Haslam McKenzie 2010). Moreover, existing residents worry that medium-density infill will introduce 'undesirable' people into traditional family orientated suburbs, in turn leading to increased social problems and falling property values (Burke 1991). Finally, many communities are increasingly distrustful of a neoliberal planning system that they see as a tool of property developers (Kwok, Johnson, and Pojani 2018).

\section{Regulatory barriers}

The literature indicates the main regulatory barriers in many cities are a lack of containment policies on the urban periphery (Alexander and Greive 2010), an absence of government leadership and communication strategies related to medium-density infill (Rowley and Phibbs 2012), and a lack of government incentives to encourage a shift away from business as usual development (Newton 2010). Other regulatory barriers are Local Government level hostility to infill (Dovey and Woodcock 2014; Hurley, Taylor, and Dodson 2017; Farris 2001), prolonged Local Government planning approvals (Rowley and Phibbs 2012), a lack of Local Government expertise to navigate the complexity of medium-density infill (Dovey and Woodcock 2014), and overly-prescriptive requirements (such as those for car parking) which limit site-specific design opportunities and the diversity of building types that can be achieved (Murray et al. 2015).

\section{Development feasibility barriers}

The literature indicates that there are a plethora of feasibility related barriers to mediumdensity infill development. These include uncertain demand (Sharam, Bryant, and Alves 2015), difficulties of obtaining finance for development (Sharam, Bryant, and Alves 2015; Burke 1991), inflated construction and labour costs, uncertainties of service infrastructure delivery (Rowley and Phibbs 2012; Farris 2001), problematic and unattractive sites (Spira 2013), fragmented land ownership and land assembly challenges (Murphy 2012; Farris 2001; Kellett and Hamnett 2017), property owners who view the value of their properties as higher than current market prices (Newton 2010), 'excessive' car parking requirements (Holling and Haslam McKenzie 2010; Burke 1991; Dittmar, Belzer, and Autler 2004), and a lack of exemplars (Newton 2010). Moreover, the marketing costs of medium-density infill are expensive because of its 'image' problem which requires an 'effective and sustained marketing strategy to overcome' (Burke 1991, 163). These challenges are compounded by a shortage of economic incentives for developers undertaking medium-density infill development (Urban Development Institute of Australia 2011) even though the 'financial odds are stacked against new multi-unit medium density developments' (Burke 1991). 


\section{The missing middle in Perth}

Many of these barriers to medium-density infill development exist in our case study city, Perth. As a result, despite a comparatively modest target for $47 \%$ urban infill, this is generally not achieved (Department of Planning Lands and Heritage 2017). Furthermore, data from the Australian Bureau of Statistics show that in $2017,73 \%$ of all residential development was detached houses (Australian Bureau of Statistics 2018). The national average for detached houses in 2017 was lower, at 53\%. Only $13 \%$ of all residential development was 'medium-density' which the Australian Bureau of Statistics classes as semi-detached, townhouses and flats, units or apartments between one and three storeys (Australian Bureau of Statistics 2018). This figure compares to the national percentage of $19 \%$. In Perth, $14 \%$ of all new residential dwellings were flats/units/apartments, four storeys and above. The national percentage was 27\% (Australian Bureau of Statistics 2018). These figures are confirmed by data from Bankwest which shows that Western Australia and Perth, in particular, has the lowest percentage of medium-density dwelling approvals (28\%) of any other mainland State (Bankwest 2017). The Australian Capital Territory has $81 \%$, New South Wales has 60\%, Victoria 48\%, and South Australia 31\% (Bankwest 2017).

Moreover, notwithstanding Activity Centre and Activity Corridor policies being the flagships of the Western Australian State Government Transit Oriented Development planning, a substantial volume of low-density urban infill development is happening through the subdivision of suburban lots in Perth's inner and middle suburbs. This development is referred to as 'background' infill - namely, small projects that yield fewer than five group dwellings (Department of Planning and Western Australian Planning Commission 2014) (Figure 2). It

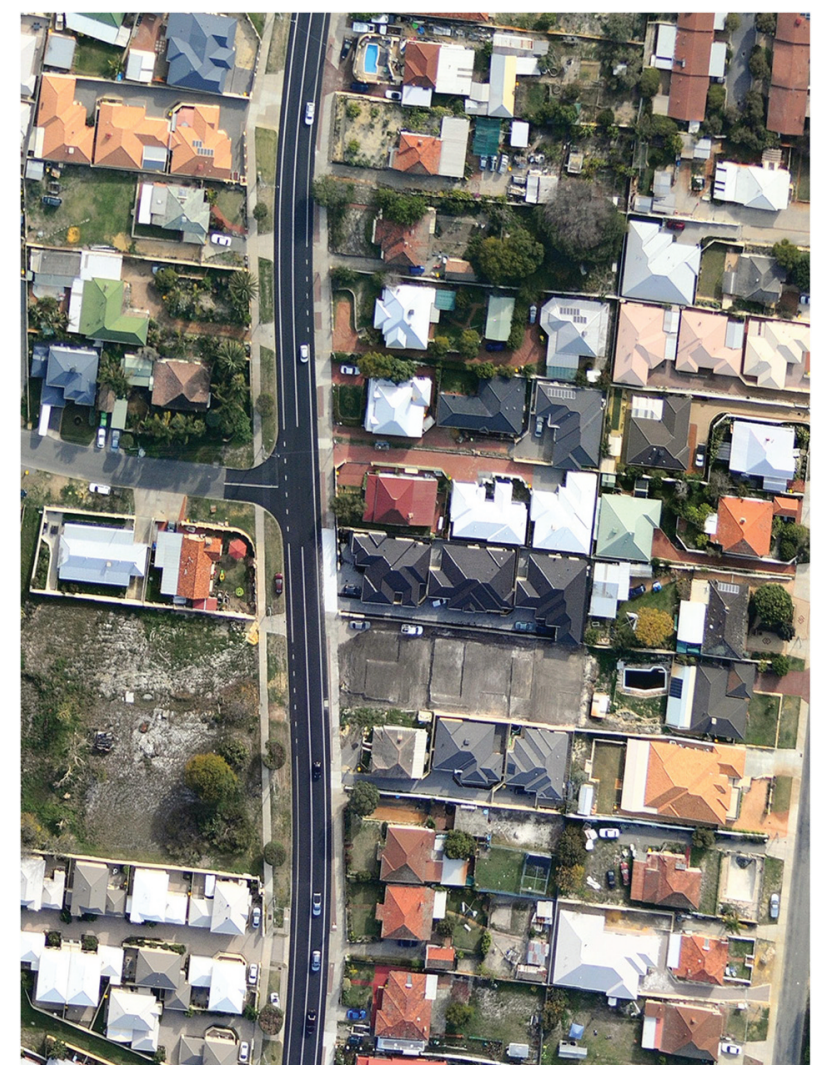

Figure 2. Background infill comprises small scale projects yielding fewer than five group dwellings. Aerial photo courtesy of Nearmaps. 
differs from the multi-unit medium-density development, which is aimed to 'plug' the missing middle because it involves the subdivision of land rather than the subdivision of airspace (Sharam, Bryant, and Alves 2015) and is typically low density. This form of development is controlled through the State Government administered Residential Design Codes (West Australian Planning Commission and Department of Planning 2015) and Local Government planning schemes which stipulate maximum residential densities (Figure 3).

Despite such planning, most of this background infill has occurred outside of Perth's Activity Centre and corridor network, and also not within a walkable catchment of mass transit (Figure 4). Moreover, single storey large building footprints covering a high percentage of the site area result in residual and unusable open spaces; minimal tree canopy, solar access and cross-ventilation; and, typically, poor resource efficiency, and water and urban heat performance (Renouf et al. 2020).

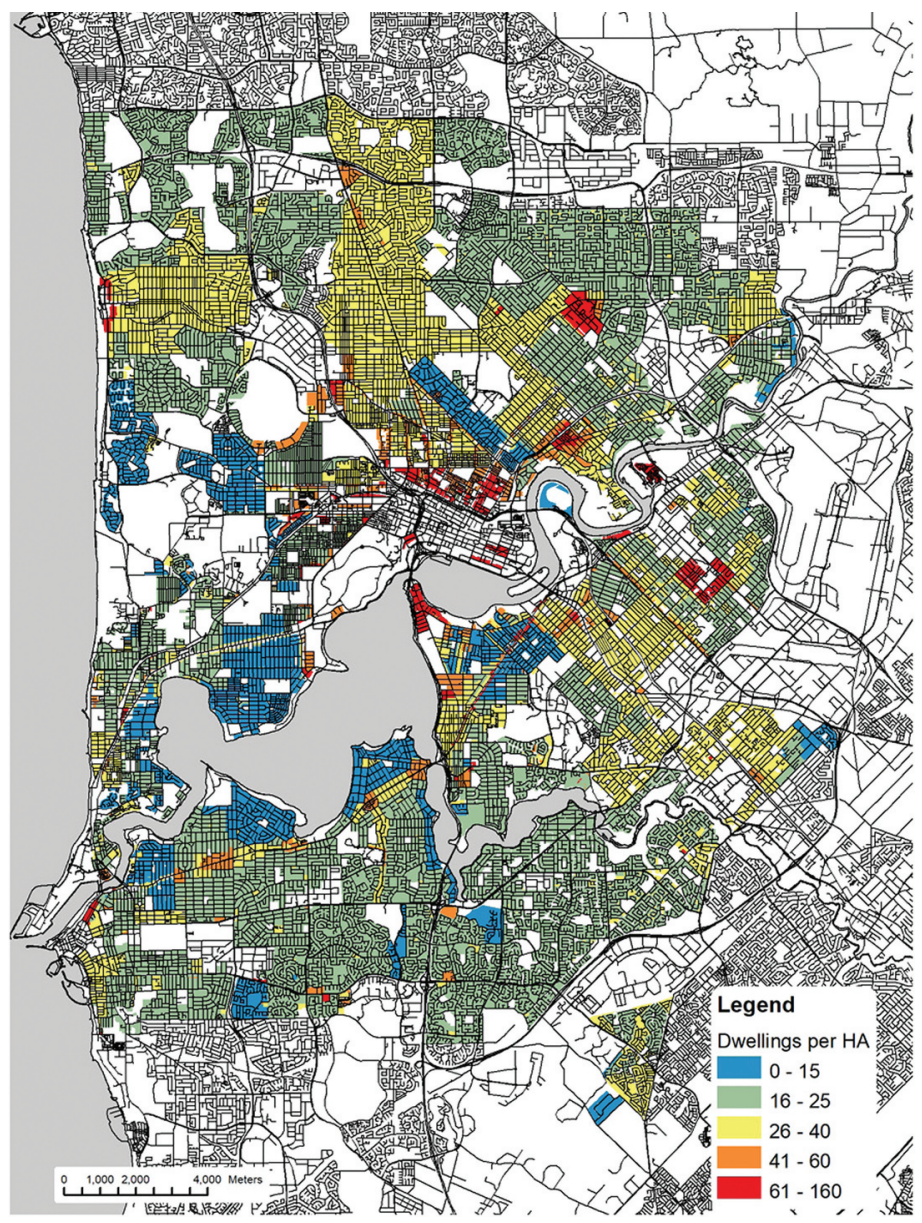

Figure 3. Zoned maximum residential densities for infill development set out in Local Government planning schemes. Map by the authors based on data from the Department of Planning, Lands and Heritage. 


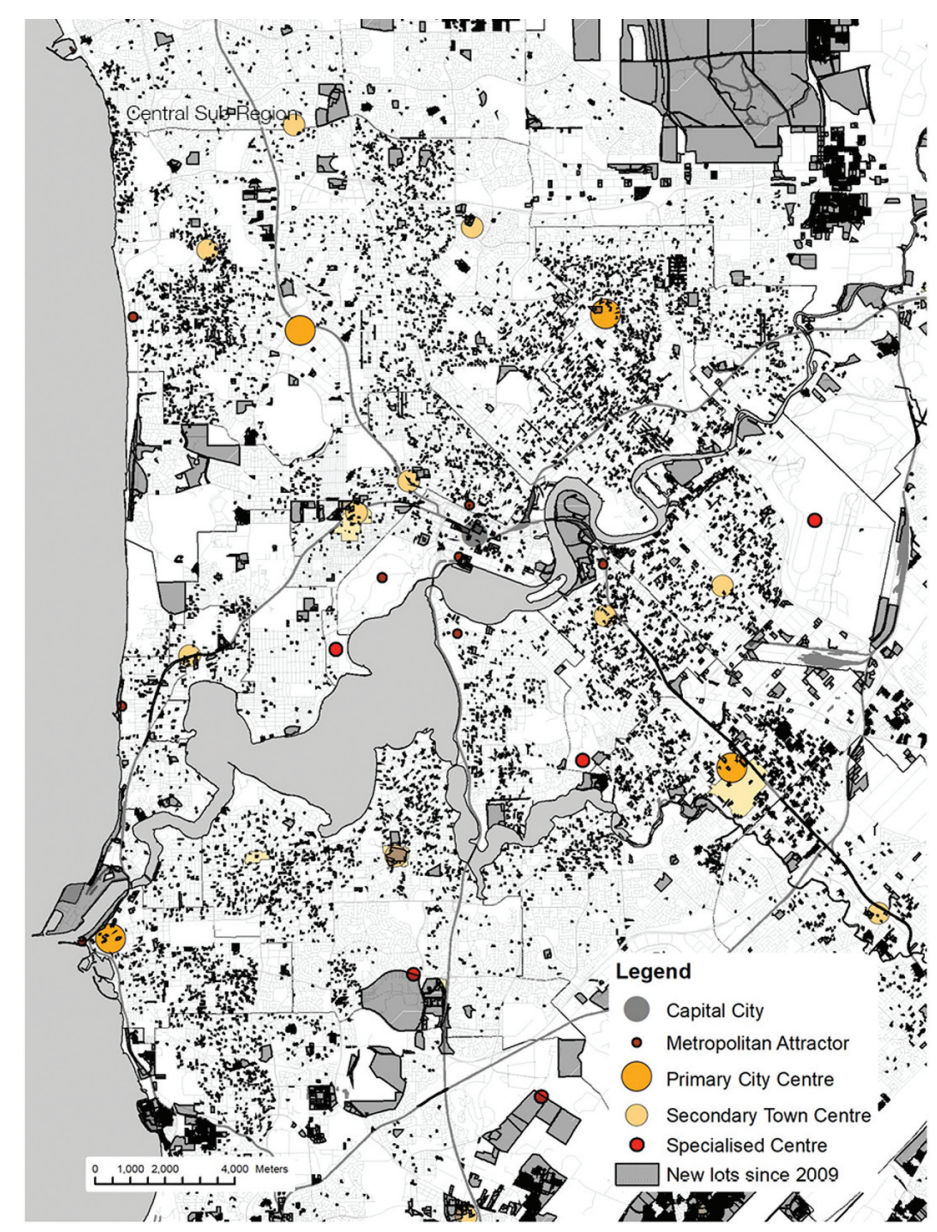

Figure 4. Perth's Activity Centre network overlaid with ad-hoc background infill development. Most infill has occurred outside of Perth's Activity Centre network and not within a walkable catchment of mass transit. Map by the authors based on data from the Department of Planning, Lands and Heritage and Landgate.

\section{A gap in the literature}

While the barriers to medium-density infill are well covered in the literature (Newton 2010), the question remains as to whether they apply in Perth, a city with an entrenched preference for suburban living (Curtin University and Hames Sharley 2013), and what potential strategies might assist in mitigating these barriers. Steven Rowley and Peter Phibbs (2012) researched the barriers to medium-density housing in Perth. Their project brought together experts from the public and private sectors to identify a comprehensive list of barriers to coordinated infill development. While this research is a touchstone for this paper, it is now dated because development conditions have degraded since 2012, and house prices have fallen significantly (Leishmann 2019). This present article updates such important stakeholder engagement work and speaks to the persistence of the problem of delivering the missing middle. Moreover, the Western 
Australian Department of Planning Lands and Heritage are currently preparing a guide for medium-density infill and thus identifying possible strategies to overcome the barriers are essential to inform and implement this policy.

To identify the barriers to medium-density development in Perth, a series of interviews with stakeholders were conducted. This paper presents an overview of these interview findings and sets forth possible strategies for mitigating these barriers. Two main questions guide this paper:

What are the predominant barriers to the delivery of medium-density urban infill development?

and

What approaches can spatial planners employ to alleviate the barriers to medium-density urban infill development?

\section{Methodology}

\section{Conceptual framework}

This paper's conceptual framework (Figure 5) presumes that many 'webs of relations' are drawn into the urban development process (Graham and Healey 1999, 633). These encompass the networks of landowners, developers, financiers, end-users, state and local governments, local politics, national politics, and pressure groups of all kinds' (Graham and Healey 1999). Indeed, in many cities, the political process is manipulated by powerful developers who can 'make their opinions felt among the elected decision-makers' (Porteous in Scott and Roweis 1977, 1115). Moreover, comprehensive community support is required for substantial development to occur (Willing and Pojani 2017). Finally, there are substantial fixed costs invested in built form, which means 'it is only with a great rarity that private landowners and land users can respond, even in the medium term to planning policy (Scott and Roweis 1977, 1107).

In this complex web, the planning process can often be described as 'disjointed incrementalism' or 'muddling through' (Hall 2014, 397). Indeed, a neoliberal, market centred approach dominates in Australia where planners zone areas for medium-density infill development and the private sector is expected, somehow, to deliver on policy goals in relation to incremental urban change. In this context, the 'planning system is presented as a permit-issuing framework for "customers" in the property market' (Gleeson and Low 2000, 20). Such approaches can lead to planners' enabling medium-density infill development through planning, but developers failing to deliver such development, because of a series of community, regulatory or development feasibility related barriers.

Nonetheless, the urban development process consists of systems which can be modified to greater or lesser degrees by the decisions and acts of planners (Wilson in Scott and Roweis 1977). Given this situation, this paper focusses on systematically assessing what community, regulatory and development feasibility barriers exist to developers delivering medium-density infill, and how they can be mitigated so that spatial planners can successfully engage with the complex 'webs of relations' which are required to deliver the missing middle. 


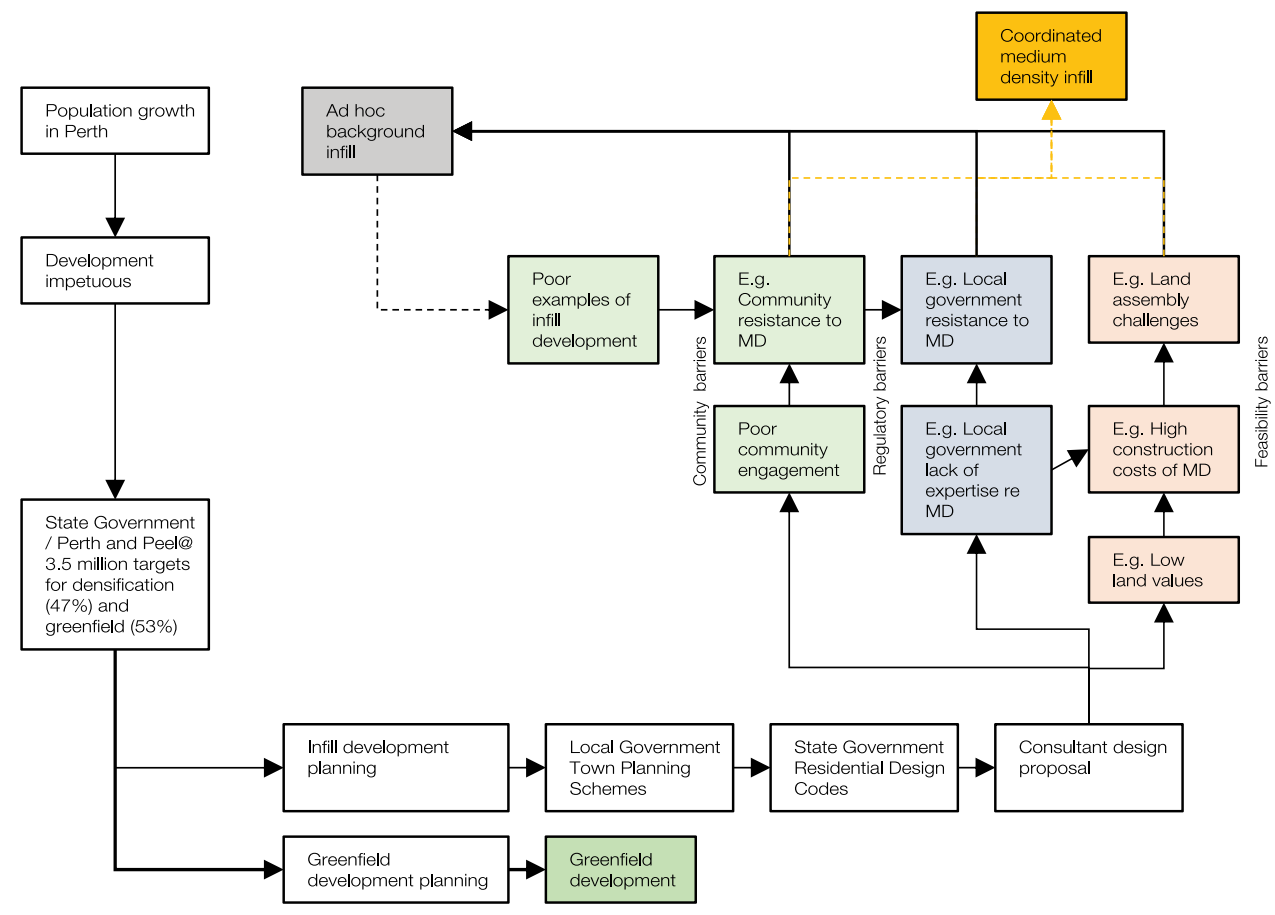

Figure 5. The project conceptual framework identifies a plethora of interconnected barriers to the development of coordinated medium-density infill development. Diagram by the authors.

\section{Methods}

To deliver on the objectives of the research, 16 face-to-face, semi-structured interviews were conducted (using pre-determined questions and asking additional questions based on the responses). Interviewees were asked about their opinions on the status of mediumdensity infill in Perth, obstacles to delivering medium-density development, and their recommendations for strategies to mitigate these barriers. The sample of interviewees was not large but sits within the recommended range of qualitative research of 5 to 50 participants (Dworkin 2012, 1319). The sample size used in qualitative research is often modest because it is concerned with gaining an in-depth understanding of a particular issue, rather than generalizing to a larger population (Dworkin 2012, 1319).

Initially purposive sampling was employed (Kelley et al. 2003) to select the interviewees. Interviewees selected included developers (3), development institute representatives (1) architects (3) planners from government (2) and industry (2), urban designers (1) politicians (2), engineers (1), and community representatives (1) who are engaged in aspects of the planning, design, approval and delivery of medium-density. There was some variation in the sample as to professional expertise, age, gender and background, however as a purposive, and not a representative sample was recruited, the background of respondents was not of importance. Respondents were recruited through appropriate representatives of related government departments. After exhausting these avenues to recruit respondents, a snowballing sampling method was utilized, whereby as one individual was interviewed; they were invited to recommend others to be interviewed. 
The interviews lasted between 30 and 60 minutes, and were recorded and transcribed verbatim after completion, yielding hundreds of pages of text. NVivo, a qualitative data analysis software package, designed for research involving very rich text-based information, was then utilized. In Nvivo, the interview transcripts were coded against over 20 barriers to medium-density infill and over 20 strategies for mitigating the barriers. An iterative process was undertaken to identify the major themes. While the result section sets out how often a particular barrier or mitigation strategy was coded, these data are indicative only reflecting the limited sample size by quantitative terms.

The study focused on existing suburban areas, which dominate Perth and which planners have zoned for a residential density of between 40 and 100 dwellings per hectare (Figure 2). These areas are generally the 'greyfields' which comprise ageing, occupied residential suburbs which often comprise under-capitalized real estate assets with some proximity to public transport (Newton 2010). The study also focussed on the agency of spatial planners in delivering the 'missing middle,' as such, economic incentives for developers tackling medium-density infill, for example, are outside of the scope of this necessarily brief paper.

There are many conflicting definitions of 'medium-density' development and the 'missing middle.' For this paper, medium-density development is defined as between 40 and 100 dwellings per hectare (net density) and two and five stories high (Figure 6). This development encompasses 2 to 3 storey terrace housing, maisonette housing, dual occupancy housing, townhouse housing, through to five-storey low-rise apartments. The reference to 'existing planning policies,' in this paper, includes 'Perth and Peel @3.5 million,' the principal plan for Perth and its Activity Centre network (Department of Planning Lands and Heritage 2018). At a finer scale, the State Government administered Residential Design Codes provide a comprehensive basis for the control of residential development above 40 dwellings per hectare so that it 'embodies an appropriate response to local amenity and place' (Department of Planning Lands and Heritage 2015, 2). These codes focus on the streetscape, site planning and building design and stipulate maximum building heights and permissible overshadowing, minimum lot boundary setbacks, visual privacy requirements, and the

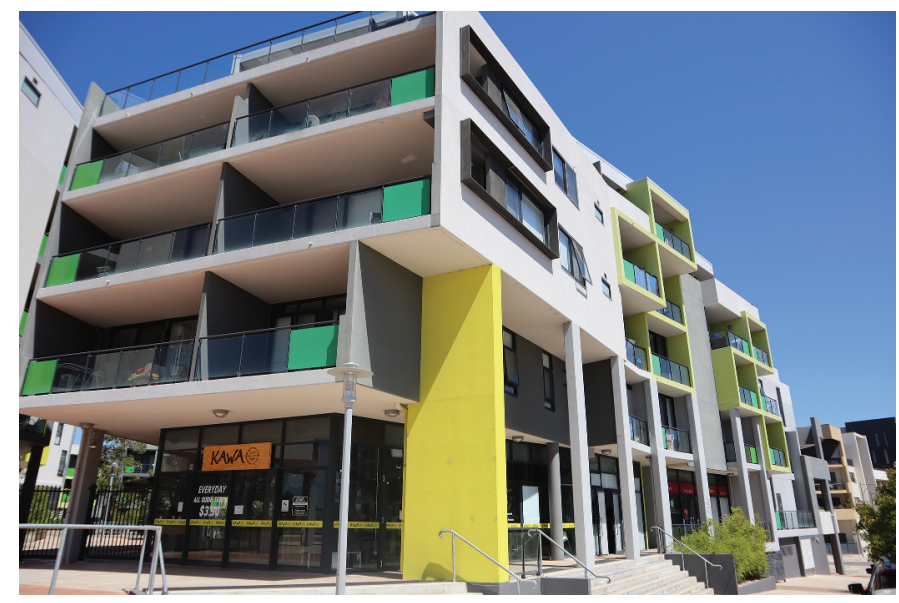

Figure 6. Coordinated medium-density, low-rise apartment development at Cockburn Activity Centre in Perth's south. Photo by the authors. 
provision of private outdoor living spaces and communal open spaces (West Australian Planning Commission, and Department of Planning 2015). Other policies include the recently released state government design guide for apartments (Department of Planning Lands and Heritage 2016), informed in part by New South Wales's State Environmental Planning Policy 65 Apartment Design Guide.

\section{Results}

Semi-structured interviews were conducted with people engaged in aspects of the planning, design, approval and delivery of medium-density infill in Perth - and asked them to identify obstacles to medium-density, and strategies to mitigate these barriers.

\section{The barriers to medium-density infill development}

The graph (Figure 7) identifies 19 themes that arose from the interviews and their dominance measured by their proportion of all the Nvivo coded references (how often this was mentioned). ${ }^{1}$ For clarity, these are grouped into three overarching themes concerning community, regulatory and development feasibility, as set out below.

\section{Community barriers}

\section{Poor examples of low-density infill}

A substantial $25 \%$ of the Nvivo coded references ${ }^{2}$ regarded the barriers to mediumdensity infill related to the proliferation of low-density background infill, arising from

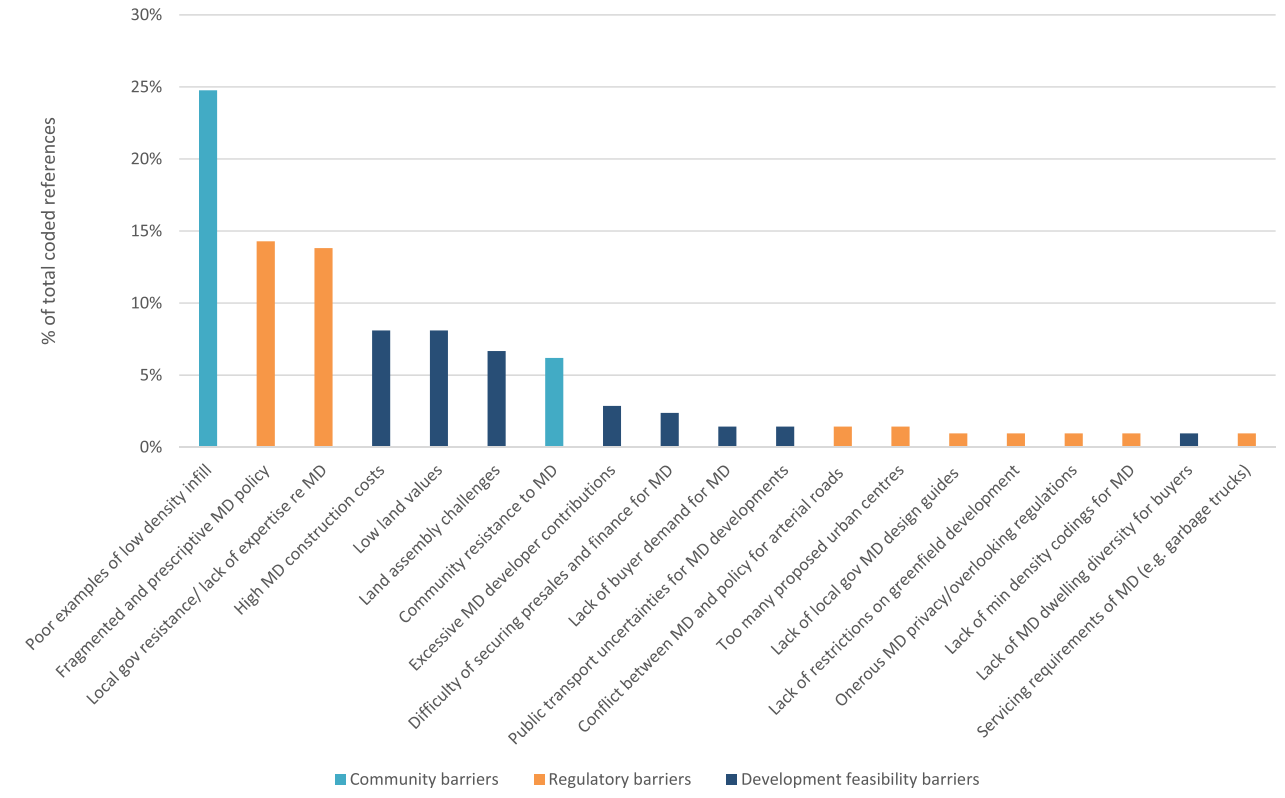

Figure 7. The barriers to medium-density infill in Perth ranked in terms of the percentage of the total number of coded references. Due to the issues of quantifying qualitative research this graph is indicative only. Graph by the authors. 
'blanket re-zonings.' Indeed interviewees identified that such examples had not sensitively considered local context, streetscape and interface, lacked mature trees, green space and amenity and resulted in predominantly-paved surfaces (planner). Interviewees criticized the Residential Design Codes for allowing such development to occur. As an interviewee reasoned, such projects could be 'fully in compliance with the Residential Design Codes, but it is not necessarily contextually responsible, high quality, or responsive to the community' (planner). The interviewees identified poor quality, lowdensity background infill as precipitating several issues, firstly, that it dissipated the development impetus from coordinated medium-density infill and second that it yielded only marginal increases in density. Established developers also cited mediocre quality urban infill as a major issue that fuels community resistance:

It makes me cringe when I see some of the developments of the last 40 years. Furthermore, that is why it is so important we get it right because otherwise, it will take a generation to rebuild the trust that we lost (developer).

The interviewees regarded that poor quality densification was particularly a problem because residents in Perth had a strong underlying affinity with suburban living. Interviewees noted that a substantial 'cultural shift' was needed for suburban residents to form a 'cultural appreciation of the benefits of medium-density' (designer). To enable this, interviewees felt that urban infill projects had to be not just average, but exceptional (developer).

\section{Community resistance}

A significant $6 \%$ of the Nvivo coded references to barriers to medium-density related to the uncertain conditions created by community resistance. The interviewees identified several critical reasons for this community opposition, including poor community engagement. Other factors related to perceived increased traffic and parking issues, perceived loss of suburban character, declining property values, declining privacy and amenity and the destruction of urban forests. In particular, interviewees identified that the loss of mature trees resulting from sweeping up-zonings was a significant issue for local communities. As an interviewee reasoned 'in my local experience, a loss of canopy can be quite distressing for local people, and that can lead to hostility to infill' (community representative).

Interviewees identified a lack of communication around proposed infill developments as compounding community resistance. While Local Governments are responsible for the zoned residential density of suburban areas, this is often not well communicated to existing residents. As an interviewee expounded:

Local Governments are at fault in the sense that they zone an area medium-density or high density, then a developer comes along, puts forward a proposal, and then the Local Governments do everything they can to stop it because of the backlash. They did not explain to the community what the zoning meant in terms of height because they are poorly engaged and advertised, and then the developers 'cop it' (politician). 


\section{Regulatory barriers}

\section{Fragmented and prescriptive medium-density policy}

A significant $14 \%$ of Nvivo coded references linked to the inadequacies of existing planning policies. Interviewees regarded that developers needed a consistent State Government medium-density development policy to increase project feasibility through minimizing the confusion of navigating conflicting Local Government policies (developer; politician). Interviewees elucidated that where local guidelines existed for medium-density development, there was little consistency or coherence between the policies, which in turn resulted in uncertainty and decreased development feasibility. As one interviewee explained:

You know, developers and the Property Council are not going to sign up for medium-density unless there is some more consistency across the board (politician).

While the Residential Design Codes do provide a degree of consistency, they were disparaged for their prescriptive nature (designer; planner). Concerning this, interviewees identified onerous State Government prescribed car-parking requirements ${ }^{3}$ as a major economic impediment for medium-density infill, because it limits the developable area (Figure 8). As one interviewee explained 'the expectations we have in the community around parking confound the potential for quality building design outcomes' (designer). Interviewees noted that excessive parking requirements also constrain the retention and propagation of mature trees that could moderate community opposition to mediumdensity infill (planner).

\section{Local Government resistance and lack of expertise regarding medium-density development}

A substantial $14 \%$ of Nvivo coded references related to the resistance of some Local Governments (and in particular councillors). The perception of interviewees was that a 'noisy minority' of community members who oppose urban infill were disproportionally

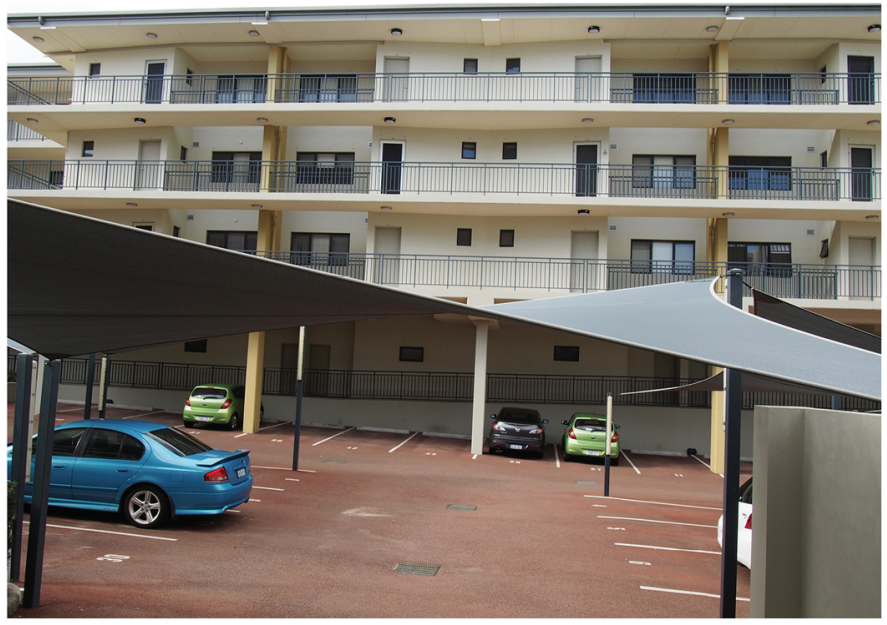

Figure 8. Interviewees felt that onerous parking requirements curtailed development feasibility for medium-density projects. Photo by the authors. 
affecting Local Government councillors. As one interviewee explained, 'the councillors respond to the community voice and as such minority groups, of 10 people, are still winning because they are voicing it through the council' (developer). Other interviewees expounded that 'until the community attitude to medium-density softens' it will result in 'resistance from many elected members' (designer). Indeed, an interviewee who is a Local Government councillor reasoned 'I am a servant of the people, and Local Government is not like State Government. If I believe, the majority of the people want X, that is what I will support: $X^{\prime}$ (politician).

Further to the effects of surly community members on councillors, interviewees recognized a 'lack of competence' and 'courage' in several councils concerning the delivery of medium-density infill (developer). Indeed, some interviewees regarded that the council officers approving medium-density development had 'a complete lack of knowledge' regarding the complexity of medium-density projects due to them being planners (designer). As one interviewee explained:

There is a lack of education on the planning and consumer side. People ring up the council and ask about a development?' Then the planner responds 'I do not know. It is compliant, or it is not compliant, I do not know whether it is good or bad, it is just compliant or not compliant' (designer).

Interviewees noted because there is generally no qualified designer at the council explaining what the 'design move' is, communities are 'in the dark' (designer) which leads to increased misunderstanding and, in turn, opposition. Moreover, due to an alleged lack of design expertise, Local Government approvals for medium-density infill developments can reputedly take 'two years' (developer) which substantially reduces project feasibility.

Other, less cited, barriers interviewees identified were too many proposed redevelopment centres, conflicts between medium-density corridors and Main Roads Department arterial road policies. Other barriers included a lack of restrictions on greenfield development, an absence of minimum density coding, onerous privacy regulations for adjoining lots and onerous garbage truck servicing requirements. Due to the necessary brevity of this paper, they have been omitted from detailed discussion; nonetheless, they remain of significance.

\section{Development feasibility barriers}

\section{High construction costs}

A significant $8 \%$ of Nvivo coded references related to high construction costs - the cost of building medium-density housing being 'considerably more per square metre' than that of detached suburban dwellings (designer). While the increased complexity of construction involved in medium-density development is a significant factor in determining cost - E.g. multi-storey construction, shared party walls, lifts, stairs, and required fire separation between dwellings - there was a perception that building medium-density development in Perth is disproportionately expensive. Interviewees perceived that this, in part, resulted from builders lacking expertise in working with alternate, lightweight construction systems that could decrease the costs of development. As a participant explained:

The cost of construction is still too high for medium-density development. That is why we end up leaning all the time on the double brick single storey stuff. As soon as you get into any sort of density, it just becomes very expensive (developer). 
A dependence on masonry construction in Perth reflects a relative oversupply of bricks and bricklayers (developer). Moreover, interviewees regarded that Perth lacked carpenters, with expertise in lightweight, timber construction techniques (developer). The result of expensive masonry construction was that potential buyers 'do the equation and calculate they are going to get a 100 square metres medium-density apartment compared with a 220 square metre house on a larger piece of land on the fringe, an equation does not stack up' in favour of apartment living (designer). These costs, in turn, result in difficulties in securing the bank finance needed to construct medium-density projects (designer).

\section{Low land values}

Eight percent of the Nvivo coded references concerning impediments to medium-density development, related to Perth's comparatively low land values which are explained by generally 'flat' economic conditions and low population growth. Interviewees felt that, as a result, medium-density development is 'going to struggle in most areas, unless you are in a prime apartment location' (planner). Interviewees also perceived that buoyant economic conditions were central to the delivery of medium-density urban infill. As one interviewee explained, 'if developers see the margins, then they will do it. The market will make it happen' (engineer).

Compounding Perth's low land values was State Government planning for urban infill. Interviewees perceived that this designated too many potential centres for densification. As one interviewee explained 'just because you have drawn a box and said, "Insert good project here," does not mean that someone is going to step in and do that' (designer) if the required development economics is not in place. Perth's Activity Centre network planning was (in particular) criticized by interviewees:

There is 93 of Activity Centres or something. You are trying to do it across too many centres, and inevitably you cannot invest as much as you would like and need to, to kick off a couple of the major ones (developer).

\section{Land assembly challenges}

Another issue hindering medium-density development in suburban sites is fragmented land ownership. Indeed, $7 \%$ of the Nvivo coded references related to land assembly challenges. As one interviewee explained, 'most significant medium-density typologies, such as low-rise apartments, require the amalgamation of sites to be feasible. The problem for developers is that lot amalgamation takes time; the time they cannot or do not want to spend' (engineer).

The result of lot amalgamation challenges is that small-scale developers deliver lowdensity background infill relatively indiscriminately throughout areas designated for increased densities. As an interviewee explained: 'Every time there is a lifting of the Residential Design Codes we just subdivide the lots whereas really what we should be doing is trying to consolidate the lots and deliver a much better outcome' (developer). This tendency reflects that there are minimal restraints on subdividing Perth's suburban lots for background infill. Other less cited barriers that interviewees identified were perceived excessive developer contributions and difficulties of securing presales and finance for medium-density development. 


\section{Mitigating the barriers to medium-density infill development}

In this section, the strategies that interviewees identified to overcome the plethora of barriers to medium-density infill are set out (Figure 9). Twenty-four different strategies were identified with overwhelming sentiment centred on eight strategies, accounting for $73 \%$ of the Nvivo coded references.

\section{Community strategies}

\section{Promote the benefits of medium-density development}

A significant $12 \%{ }^{4}$ of the Nvivo coded references related to government better selling the 'community benefits' that medium-density infill could yield (developer). As one interviewee elucidated:

I think it has a lot to do with evolving community attitudes and demonstrating the benefits of medium-density housing. I think much of that will come simply through the consistent delivery of it and understanding that it delivers better streets where people can commune with one another, it delivers better levels of service in terms of more shops within walking distance, cafes, bars, these kinds of things. The more population you have, the more intense population you have in a setting, the more that can be offered in terms of those kinds of public amenities (designer).

Interviewees considered that improvements should be generally focussed on the public domain such as streetscapes where 'proper' tree planting can reduce the perceived density of urban infill and make it less 'imposing' (developer). Interviewees recognized the upgrading

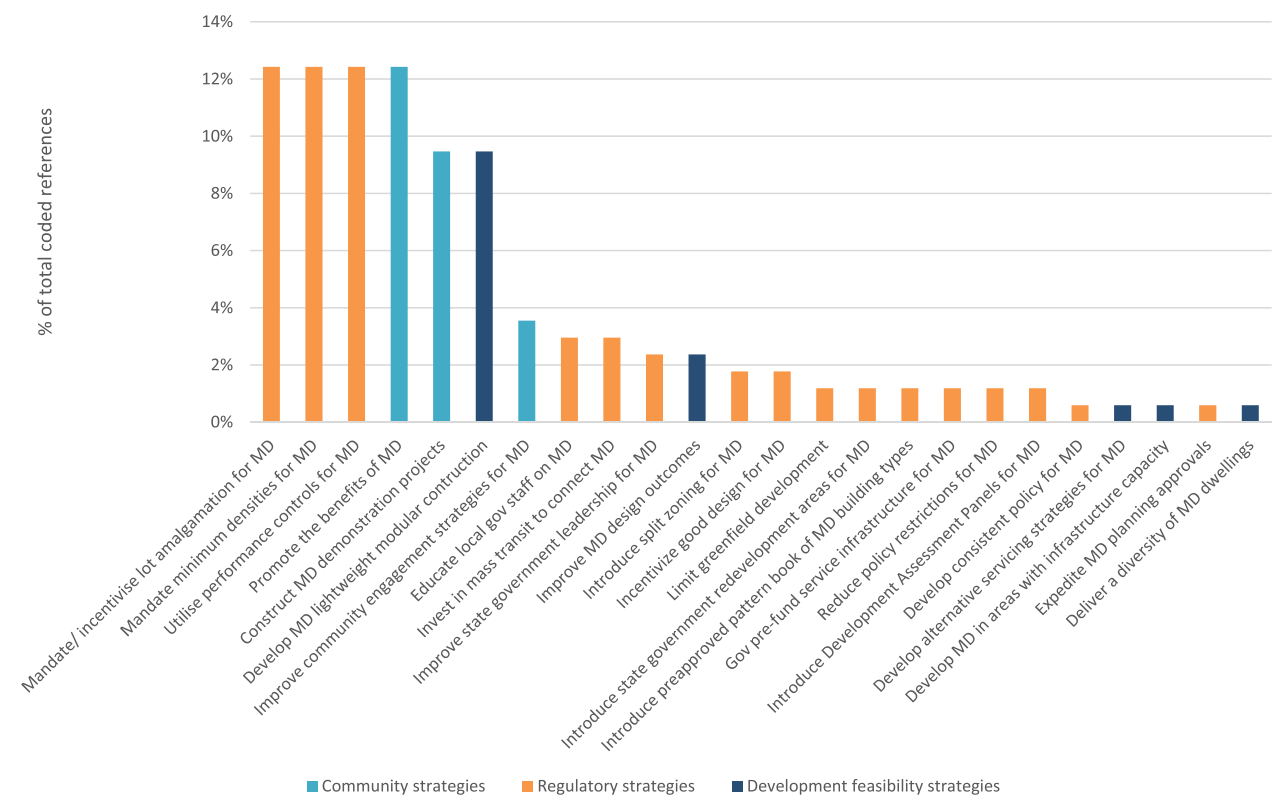

Figure 9. The strategies to mitigate the barriers to medium-density infill in Perth ranked in terms of the percentage of total coded references. Due to the issues of quantifying qualitative research this graph is indicative only. Graph by the authors. 
of local parks as a critical strategy to provide amenity to a densifying neighbourhood, but also to engender community support of medium-density development (developer, politician).

\section{Construct medium-density demonstration projects}

Overall, interviewees felt that one of the most effective strategies was the construction of demonstration projects to help alleviate community resistance to infill. Indeed, $9 \%$ of the Nvivo coded references related to the construction of demonstration projects. The interviewees indicated that pilot projects were useful in dispelling community concerns about medium-density living. As one interviewee expounded 'as we demonstrate good outcomes' I think concerned community members will go, 'oh okay, it was not such a big deal,' and community opposition will be dispelled (developer).

Interviewees felt such pilot projects should be comprehensively evaluated to benchmark their performance. Indeed, one interviewee identified that a 'long-term longitudinal research project' could assess the 'design and liveability outcomes for the residents' (engineer). As another explained:

One of the failings is we do not tend to do a review post-development, so we can go back and say, 'what was the focus of community concern?' Did those fears eventuate or not, or what mitigation strategies were adopted in the design? Did they work or not? (developer).

Interviewees regarded that such empirical, real-world data could obviate community resistance by providing 'evidence to comfort people' who are concerned about how medium-density infill is 'going to affect their wellbeing and their livelihood' (developer).

\section{Improve community engagement strategies for medium-density development}

A modest $4 \%$ of the Nvivo coded references concerning strategies to enable mediumdensity infill related to improving community engagement strategies. The interviewees felt that both local and State Government could improve strategies for appealing to local communities. As an interviewee expounded:

When you talk to most members of the community, particularly older generations, they just do not get the benefits of density. We need to sell it much better through really aggressive marketing, TV and newspaper. I think that is a massive failure of the State Government (designer).

At the Local Government level, one interviewee identified collaborative design engagement methods as useful for engaging communities regarding infill development (community representative). The toolkits are flexible, scale models which have been created to allow workshop attendees to understand, and engage with, the spatial implications of urban infill policy. One interviewee explained that this approach worked well with community members because 'there was real value in a hands-on approach' (community representative).

\section{Regulatory strategies}

\section{Mandate/incentivize lot amalgamation for medium-density development}

Interviewees stressed the importance of lot amalgamation and referred to this as the 'holy grail' regarding delivering medium-density infill development (developer). Indeed, $12 \%$ of the total Nvivo coded references related to the amalgamation of lots. The need for lot 
amalgamation was explained in terms of it allowing designers to respond to the 'site characteristics, the orientation and to achieve higher buildings and a better density return' (developer). Other interviewees believed that lot amalgamation provided 'more room to move' which, in turn, made medium-density infill 'cheaper to build, as it improves the efficiency of the site,' as well as reducing the perception of 'imposing' medium development (developer). Finally, interviewees linked larger lots to development feasibility. As one interviewee explained:

Developers just cannot get big enough slabs of dirt, so rezoning it all to 60,80 , or 100 dwellings per hectare, is meaningless unless you have a framework that pulls these lots together to give developers a decent piece of Perth to work with (developer).

Conversely, on a small lot, one interviewee explained the 'overlooking, the design, everything gets complicated, and you start annoying all your neighbours' (developer). As they reasoned: when you are trying to put '10, 15 units' on a small lot 'they are all going to be really small units, with tiny little balconies because we are trying to maximize the yield to make it work' (developer).

Interviewees identified two main strategies for achieving lot amalgamation. The first was mandating a minimum lot size for infill development. Interviewees felt that setting minimum lot sizes for urban infill development would reduce background infill and increase market demand for medium-density development (designer, politician). While an exact minimum was not generally provided one interviewee regarded this should be around ' 1,200 to 1,500 square metres' (developer), which would preclude any suburban infill unless adjoining lots could be amalgamated. This minimum would preclude the 'mum and dad investor who without even thinking ... can make money' on a 'crappy little subdivision' (developer) a situation that has led to only a 'minimal increase in the dwelling yields' of existing suburbs (developer).

Because the setting of minimum lot sizes would possibly incur 'political backlash' (engineer), some interviewees felt that the government could offer more significant incentives to encourage land amalgamation (designer; developer). These could include density bonuses, 'cash, opportunities, or swapping air rights' (developer), and split zonings that enabled higher densities for lots which have been amalgamated (planner). Interviewees felt that policymakers should only target medium-density infill in specific locations so that State Government could afford to invest in land amalgamation, community engagement and service infrastructure provision. By focussing these efforts, interviewees felt that the government should have the capacity to 'kick off a couple of the major ones' (developer).

\section{Mandate minimum densities for medium-density development}

Interviewees felt that policymakers should also establish minimum residential densities, with possible incentives for delivering development exceeding the minimum density (developer; planner). Indeed, $12 \%$ of the references related to the setting of minimum residential densities for infill development. One interviewee reasoned: 'you need to mandate minimum densities before developing infill in appropriate areas. Moreover, do not mess around with R30 or 40, but get it up to R80 or 100 ...' (community representative). Interviewees noted that once background infill had occurred, and suburban lots subdivided and strata-titled, it was challenging to adapt to medium-density over time. As one interviewee noted: 
You need to force the market to pause and stop these individual lots from being carved out because trying to unwind those strata-titled lots 20 to 30 years from now is going to be hard work (developer).

Another interviewee argued that setting minimum densities would inhibit infill development in an underperforming real estate market, rather than lead to medium-density outcomes (engineer). In response, other interviewees reasoned that it was important for policymakers to 'hold their nerve' until market conditions improved and 'forced' mediumdensity development. As one interviewee explained:

The most important thing is that planners need to have the courage to hold steady with their plans. If we sit back and look at the property cycle, what does not work today, will work in a few years. If Perth grows to a metropolitan population of three million by 2031 , it will come back; it is just at the bottom of the market now ... If we are patient and we create the appropriate frameworks, this will happen (developer).

\section{Use performance controls for medium-density development}

Twelve percent of the Nvivo coded references related to using performance and not compliance controls. As one developer argued 'from my perspective, they should be far more performance-based and less restrictive, and say you must have $\mathrm{X}, \mathrm{Y}$ and $\mathrm{Z}$. They need to be far more performance-based because that is where the innovation comes in.' Interviewees also felt that performance-based planning controls could be used to reward developers for contributions to the public domain 'if you have this many trees and you have this and this, then you can go extra floor ratio, or whatever' (designer).

Interviewees, in particular, noted that prescriptive car-parking requirements were overly onerous (planner), and affected the feasibility and amenity of medium-density projects. As an interviewee reasoned, 'We are destroying our opportunity for these places by insisting on these stupid rules for cars' (engineer). Furthermore, interviewees identified possible alternative car parking strategies that decreased private parking on mediumdensity lots and instead utilized street verges for right angle car parking. Interviewees felt that performance-based controls could enable such alternative strategies.

One of the reasons communities can oppose urban infill is because they perceive it to be an assault on the leafy, suburban character of their neighbourhoods. One interviewee proposed that tree retention could be incentivized through performance controls by rewarding the protection of trees on-site with bonuses for 'more height and more density' (planner). Another interviewee concluded 'If you retain that tree, we will give developers an extra two apartments' (politician). Given Australian communities' unreceptive attitudes to higher density developments, the use of mature trees to reduce the perceived density of infill makes sense (Figure 10).

\section{Educate Local Government staff about medium-density development}

A crucial mitigation strategy identified by interviewees was educating Local Government councillors and staff so that they can reliably appraise, and communicate the advantages of medium-density infill development (developer). Three percent of the Nvivo coded references linked to educating Local Government staff. One interviewee noted that the best way of improving design knowledge was for councils to engage a 'council architect' who could complement the skills of council planners who are often not well-versed in 


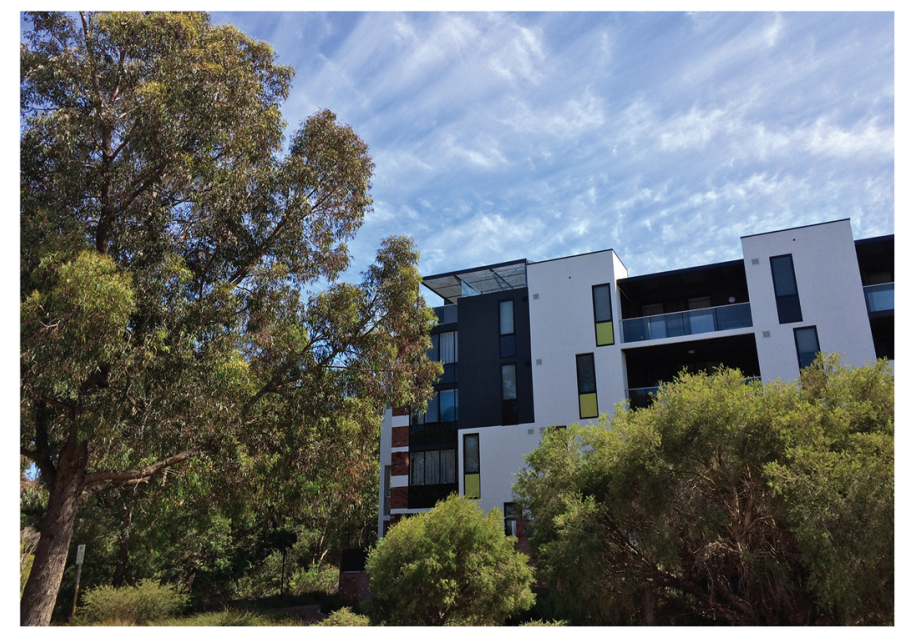

Figure 10. Mature trees can be employed to reduce the perceived density of medium-density infill development. Photo by the authors.

architectural design (designer). Moreover, some interviewees observed that a council architect could be an asset because concerned residents could contact them directly, and they could confidently explain the design intent of medium-density project (designer).

\section{Development feasibility strategies}

\section{Develop medium-density lightweight, modular construction}

Interviewees felt that the feasibility of medium-density infill development could be enhanced through the uptake of modular, lightweight, timber construction, which they regarded could decrease construction costs (designer) and even lessen community opposition because 'timber buildings are less imposing' (community representative). Indeed, $9 \%$ of the Nvivo coded references concerning strategies to enable mediumdensity infill related to alternative construction techniques.

Concerning cost, one interviewee referred to medium-density projects elsewhere in Australia which utilized timber frame, low-rise apartment buildings resulting in a cost reduction of 'at least 30\% below' conventional masonry construction (developer). However, interviewees also referred to the need to 'build up capacity and experience in the timber industry itself' (engineer) to get the 'pricing for timber frame construction close what is being achieved in elsewhere in Australian cities' (developer).

\section{Other mitigating strategies}

Other strategies, which interviewees identified, were for the State Government to invest in public transit to medium-density locations, limit greenfield development to build impetuous behind infill development, and to acquire land and pre-fund infrastructure provision in medium-density precincts - were suggested. 


\section{Discussion}

This paper has identified the impediments to medium-density infill development in Perth and considered several strategies that planners could pursue to alleviate these barriers.

\section{The findings in relation to the literature}

Interestingly one of the dominant findings of this research paper is that the delivery of medium-density infill development is contingent on limiting low-density background infill development (Bolleter 2016a). This approach is referred to in the literature as 'negative planning,' a mode of planning which excludes certain types of development (Siedentop, Fina, and Krehl 2016). Interviewees consistently made the point that the government need to set minimum lot sizes, mandate minimum density and focus on a reduced number of centres/sites. To enable a focus on selected sites, Peter Newton has suggested the nomination of 'slow-go' or 'no-go' zones which prevent major redevelopment in inappropriate areas (2010). In particular, setting minimum densities and site areas should mean that policymakers do not further propagate the fragmented piecemeal process of recent decades (Newton 2010) and squander the development opportunities that they can take full advantage of when Perth's economic conditions improve. Having patience in this respect has been one lesson from North America, where a higher rate of multi-unit construction has correlated with a favourable financial climate (Burke 1991).

These findings tally with the literature around minimum density restrictions applied by policymakers internationally to ensure sites are urbanized effectively (OECD 2012). Indeed, in Germany 'central places' are zoned with a required minimum density for new development where they 'support the efficient use of land' (Siedentop, Fina, and Krehl 2016, 74). Many cities in the United States set a minimum density requirement in their zoning ordinances (OECD 2012). Examples are in transit stations in San Jose, California and Hillsboro, Oregon (Greenberg 2004). Minimum density restrictions also feature prominently in Europe. In London boroughs, land-use plans specify a minimum density (OECD 2012), and in France, municipalities can impose minimum density requirements on new construction near sites near to mass transit (OECD 2012). Moreover, commentators have also identified the importance of local planning controls, and in particular minimum lot sizes, in determining the density of housing development (Kupke, Rossini, and Stanley 2011). Indeed a North American study suggests that with minimum lot restrictions, housing development could be up to 50\% higher in density (McConnell, Walls, and Kopits 2006).

Nonetheless, in Australia, state governments have drawn up strategic plans which facilitate rather than impede infill residential development (Kupke, Rossini, and Stanley 2011, Murphy 2012) which accords with Australia's neoliberal, market centred approach (Gleeson and Low 2000). Indeed, state intervention in the form of minimum densities and lot sizes could be unpopular with landholders and developers, and it is unclear whether state or local planning agencies would risk inflaming their ire, as growth management remains highly controversial (Siedentop, Fina, and Krehl 2016). Moreover, strong growth controls on background infill, through minimum densities and lot sizes, could lead to price inflation and thus reduce housing affordability (Murphy 2012). Nonetheless, without such restrictions in place, it will be difficult to corral the necessary drive behind medium-density infill development, in the short term at least. 
Another important finding from this paper has been that policymakers need to be realistic that most communities are not so concerned about continued suburban sprawl on the urban periphery that they will support medium-density infill in their neighbourhood. Indeed, unless residents see a direct benefit to them from urban infill, they are highly unlikely to support it. The interviewees regarded that such benefit could take the form of public domain upgrades, focussing on both streets (Bolleter 2016b) and parks (Bolleter and Ramalho 2019, 2014; Bolleter 2017b). This finding resonates with the literature. The British sociologist, Peter Marris, argued that 'people cannot reconcile themselves to the loss of familiar attachments in terms of some impersonal utilitarian calculation of the common good. They have to find their own meaning in these changes before they can live with them' (In Sarkissian 2013). One example of a policy which provides an incentive to local communities to support density is Social Bonus Zoning in Vancouver which allows higher density development in exchange for improved public amenities (Kelly, Breadon, and Reichl 2011). As Murray et al. point out:

Communities are not averse to higher density redevelopment as long as it 'gives something back' to the existing area. Residents are far less resistant to urban change than one might expect. In fact, redevelopment is welcomed if it contributes to local community building and improvements to public amenity (Murray et al. 2015, 112).

Furthermore, physical enhancements in the public realm can have positive 'spill-over effects' on surrounding property values, increasing the feasibility of private sector infill activity over time. (Murray et al. 2015).

Another finding is the importance of exemplar projects - tailored to specific precincts and populations - to shift community sentiment, a finding which tallies with the literature (Newton and Glackin 2014; Newton et al. 2011). Demonstration projects such as the WGV development in Perth - which showcases a denser, more sustainable housing product with shared infrastructure and services - anecdotally have been successful in reducing community resistance to densification since construction (Wiktorowicz et al. 2018, 64).

\section{The findings in relation to the Perth focussed literature}

The findings from the interviewees generally tally with those from the stakeholder engagement work conducted by Steven Rowley and Peter Phibbs in 2012, as discussed earlier. The barriers identified in this project resonate with those tabled in this paper, including a lack of suitable sites, high construction costs, difficulties in securing finance, the complexity of the approval process, and community opposition (Rowley and Phibbs 2012). This comparison indicates that many of the obstacles to medium-density have been long-standing in Perth and are highly unlikely to disappear without targeted policy interventions such as this paper proposes.

Some of the mitigating strategies from the Rowley and Phibbs study resonate with this one. Similarly, they also found that 'erroneous perceptions of medium-high-density development' (Rowley and Phibbs 2012, 23) needed to be counteracted by high-quality pilot projects. The Rowley and Phibbs study also noted that there should be sufficient flexibility built into the development approval system to allow developers to reduce planning control requirements (e.g. parking) if they can provide a compelling reason for doing so (Rowley and Phibbs 2012). 
Where the two research projects differ is the in the willingness of the interviewees in this paper to suggest draconian measures - at least by Perth standards - to limit background infill through mandated minimum densities, minimum lot sizes for infill development and a reduced number of centres. This willingness reflected a deep sense of frustration with the persisting inability to overcome the barriers to medium-density infill development.

\section{Policy implications}

The strategies for achieving medium-density development that interviewees noted, in some cases, conflict with current planning. A refocussing of medium-density development efforts on a limited number of sites contradicts Perth's overarching planning document which sets out a substantial 93 Activity Centres sites (Department of Planning Lands and Heritage 2018).

The setting of minimum densities challenges existing Local Government zonings which typically denote only maximum densities (Department of Planning Lands and Heritage 2015). While the Residential Design Codes document sets out minimum lot areas for infill development, these are comparatively small in size and do not preclude 'business as usual' background infill development (Department of Planning Lands and Heritage 2015). The Residential Design Codes are also prescriptive and do not allow designers and developers freedom to innovate with alternative tree retention, building height and car parking propositions (Department of Planning Lands and Heritage 2015).

Several strategies proposed in this paper align with the Design WA apartment design guide. The guide echoes the views of the interviewees - in particular concerning its support for lot amalgamation, mature tree retention, deep soil area provision, and for 'well-designed taller buildings with good siting and setbacks' (Department of Planning Lands and Heritage 2016, 34). The Western Australian Department of Planning Lands and Heritage is also preparing a related guide for medium-density infill development. The strategies set out in this paper should inform the requirements of this new policy/design guide.

\section{Conclusion}

The capacity to deliver medium-density development - and curtail excessive sprawl - will be a challenge that will define the liveability and viability of Perth - and similar cities - in this century. This paper has sought to understand why planners are struggling to deliver medium-density infill development and what can be done to address this situation. In conclusion, planners should promote the benefits of medium-density infill that deliver local tangible benefits for existing residents. Moreover, planners should critically assess State Government planning to limit the number of sites zoned for infill development and set minimum lot sizes and residential densities for infill development. This will avert 'business as usual' background infill which has considerable negative influence on urban liveability and amenity (Renouf et al. 2020). Without such restrictions in place, it will be exceedingly difficult for developers to corral the required impetus behind medium-density infill development. Such policy shifts will be hard to implement, which is the reason they have been avoided till now. However, the sustainability and liveability issues faced by Australian cities means that their avoidance is no longer a viable option. 


\section{Notes}

1. Due to the issues of quantifying qualitative research these are indicative only.

2. In total there were $\mathbf{2 1 0}$ Nvivo coded references to the barriers.

3. In Perth, policies instruct that 1 bedroom dwellings provide between 0.75 and 1 bay, $>2$ bedroom dwellings 1 to 1.25 bays, in addition to visitor parking (Department of Planning Lands and Heritage 2016, 81), regulations that are generally in accordance with buyer expectations.

4. There were 169 Nvivo coded references to mitigation strategies in total.

\section{Acknowledgments}

The authors would like to thank the Western Australian Planning Commission, the Department of Planning Lands and Heritage, DevelopmentWA, and the Department of Communities for their generous support for our research.

\section{Disclosure statement}

No potential conflict of interest was reported by the authors.

\section{Funding}

This work was supported by the Western Australian Planning Commission; Department of Communities; DevelopmentWA; Department of Planning Lands and heritage.

\section{References}

Alexander, I., and S. Greive. 2010. "Metropolitan Development in Perth: Strategic Planning or Strategic Spin?" In Planning Perspectives from Western Australia: A Reader in Theory and Practice, edited by I. Alexander, S. Greive, and D. Hedgcock, 48-65. Perth: Fremantle Press.

Arvola, A., and K. Pennanen. 2014. “Understanding Residents' Attitudes Towards Infill Development At Finnish Urban Suburbs." World SB14 Barcelona, Barcelona, September 30.

Australian Bureau of Statistics. 2018. "8731.0 - Building Approvals, Australia, May 2018." Australian Bureau of Statistics. Accessed July 18. http://www.abs.gov.au/Ausstats/abs@.nsf/mf/8731.0

Bankwest. 2017. 2017 Housing Density Report.

Bolleter, J. 2016a. "Background Noise: A Review of the Effects of Background Infill on Urban Liveability in Perth." Australian Planner 10: 1-14.

Bolleter, J. 2016b. "On the Verge: Re-thinking Street Reserves in Relation to Suburban Densification." Journal of Urban Design 21: 195-212. doi:10.1080/13574809.2015.1133229.

Bolleter, J. 2017a. "Fringe Benefits? A Review of Outer Suburban Development on Perth's Fringes in Relation to State Government Goals Concerning the Natural Environment and Efficient Transport Connectivity." Australian Planner 54 (2): 93-114. doi:10.1080/07293682.2017.1319395.

Bolleter, J. 2017b. “Living Streams for Living Suburbs: How Urban Design Strategies Can Enhance the Amenity Provided by Living Stream Orientated Public Open Space." Journal of Urban Design 23 (4): 518-543. doi:10.1080/13574809.2017.1362953.

Bolleter, J., and C. Ramalho. 2014. "The Potential of Ecologically Enhanced Urban Parks to Encourage and Catalyze Densification in Greyfield Suburbs." Journal of Landscape Architecture 9 (3): 54-65. doi:10.1080/18626033.2015.968418.

Bolleter, J., and C. Ramalho. 2019. Greenspace-Oriented Development: Reconciling Urban Density and Nature in Suburban Cities. London: Springer. 
Bolleter, J., and R. Weller. 2013. Made in Australia: The Future of Australian Cities. Perth: University of Western Australia Publishing.

Burke, T. 1991. "Medium Density Housing in the United States: Implications for Australia." Urban Policy and Research 9 (3): 157-169. doi:10.1080/08111149108551500.

Curtin University, and Hames Sharley. 2013. The Housing We'd Choose: A Study for Perth and Peel. Department of Housing, Department of Planning.

Department of Planning Lands and Heritage. 2015. SPP3.1: Residential Design Codes. Western Australian Planning Commission.

Department of Planning Lands and Heritage. 2016. State Planning Policy 7.3 Residential Design Codes - Apartments. Western Australian Planning Commission.

Department of Planning Lands and Heritage. 2017. Urban Growth Monitor: Perth Metropolitan, Peel and Greater Bunbury Regions. Western Australian Planning Commission.

Department of Planning Lands and Heritage. 2018. Perth and Peel @3.5 million. Western Australian Planning Commission.

Department of Planning, and Western Australian Planning Commission. 2014. Urban Growth Monitor: Perth Metropolitan, Peel and Greater Bunbury Regions. Western Australian Planning Commission.

Dittmar, H., D. Belzer, and G. Autler. 2004. "An Introduction to Transit-Oriented Development." In New Transit Town: Best Practices in Transit-oriented Development, edited by H. Dittmar and G. Ohland, 2-18. Washington: Island Press.

Dodson, J. 2010. "In the Wrong Place at the Wrong Time? Assessing Some Planning, Transport and Housing Market Limits to Urban Consolidation Policies." Urban Policy and Research 28 (4): 487-504. doi:10.1080/08111146.2010.517158.

Dovey, K., and I. Woodcock. 2014. Intensifying Melbourne: Transit-orientated Urban Design for Resilient Urban Futures. Melbourne: Melbourne School of Design, The University of Melbourne.

Dworkin, S. 2012. "Sample Size Policy for Qualitative Studies Using In-Depth Interviews." Archives of Sexuality Behavior 41: 1319-1320. doi:10.1007/s10508-012-0016-6.

Farris, T. 2001. "The Barriers to Using Urban Infill Development to Achieve Smart Growth." Housing Policy Debate 12 (1): 1-30. doi:10.1080/10511482.2001.9521395.

Gleeson, B., and N. Low. 2000. "'Unfinished Business': Neoliberal Planning Reform in Australia." Urban Policy and Research 18 (1): 7-28. doi:10.1080/08111140008727821.

Graham, S., and P. Healey. 1999. "Relational Concepts of Space and Place: Issues for Planning Theory and Practice." European Planning Studies 7 (5): 623-646. doi:10.1080/09654319908720542.

Greenberg, E. 2004. "Regulations Shape Reality: Zoning for Transit-Oriented Development." In New Transit Town: Best Practices in Transit-oriented Development, edited by H. Dittmar and G. Ohland, 58-82. Washington: Island Press.

Hall, P. 2014. Cities of Tomorrow; an Intellectual History of Urban Planning and Design since 1880. 4th ed. Oxford: Blackwell Publishing.

Holling, C., and F. Haslam McKenzie. 2010. "Integrated Transit Orientated Development: Is It Appropriate for Perth?" In Planning Perspectives from Western Australia: A Reader in Theory and Practice, edited by I. Alexander, S. Greive, and D. Hedgcock, 274-288. Perth: Fremantle Press.

Hurley, J., E. Taylor, and J. Dodson. 2017. "Why Has Urban Consolidation Been so Difficult?" In The Routledge Handbook of Australian Urban and Regional Planning, edited by N. Sipe and K. Vella, 123-135. New York: Routledge.

Kellett, J., and S. Hamnett. 2017. "Adelaide: Tough Times in the City of Light." In Planning Metropolitan Australia, edited by S. Hamnett and R. Freestone, 109-131. New York: Routledge.

Kelley, K., B. Clark, V. Brown, and J. Sitzia. 2003. "Good Practice in the Conduct and Reporting of Survey Research." International Journal for Quality in Health Care 15 (3): 261-266. doi:10.1093/ intqhe/mzg031.

Kelly, J.-F., and P. Donegan. 2015. City Limits: Why Australian Cities are Broken and How We Can Fix Them. Melbourne: Melbourne University Press.

Kelly, J.-F., P. Breadon, and J. Reichl. 2011. Getting the Housing We Want. Melbourne: Grattan Institute. 
Kupke, V., P. Rossini, and M. Stanley. 2011. "A Multivariate Study of Medium Density Housing Development and Neighbourhood Change within Australian Cities." Pacific Rim Property Research Journal 17 (1): 3-23. doi:10.1080/14445921.2011.11104315.

Kwok, M., L. Johnson, and D. Pojani. 2018. "Discretion and the Erosion of Community Trust on Planning: Reflections on the Post-Political." Geographical Research 56 (4): 382-392. doi:10.1111/ 1745-5871.12310.

Leishmann, C. 2019. "Why Falling House Prices Do Less to Improve Affordability than You Might Think." The Conversation. Accessed September 25. https://theconversation.com/why-fallinghouse-prices-do-less-to-improve-affordability-than-you-might-think-111267

Maginn, P., and N. Foley. 2017. "Perth: From 'Large Provincial City' to 'Globalizing City'." In Planning Metropolitan Australia, edited by S. Hamnett and R. Freestone, 124-147. New York: Routledge.

McConnell, V., M. Walls, and E. Kopits. 2006. "Zoning, TDRs and the Density of Development." Journal of Urban Economics 59 (3): 440-457. doi:10.1016/j.jue.2005.12.005.

Murphy, P. 2012. "The Metropolis." In Planning Australia: An Overview of Urban and Regional Planning, edited by P. Maginn and S. Thompson, 155-179. Melbourne: Cambridge University Press.

Murray, S. 2013. "Infill Precincts." In Made in Australia: The Future of Australian Cities, edited by J. Bolleter and R. Weller, 290-297. Perth: University of Western Australia Publishing.

Murray, S., N. Bertram, L.-A. Khor, D. Rowe, B. Meyer, P. Newton, S. Glackin, T. Alves, and R. McGauran. 2015. Processes for Developing Affordable and Sustainable Medium Density Housing Models for Greyfield Precincts. Melbourne: Australian Housing and Urban Research Institute.

Newton, P. 2010. "Beyond Greenfield and Brownfield: The Challenge of Regenerating Australia's Greyfield Suburbs." Built Environment 36 (1): 81-104. doi:10.2148/benv.36.1.81.

Newton, P., and S. Glackin. 2014. "Understanding Infill: Towards New Policy and Practice for Urban Regeneration in the Established Suburbs of Australia's Cities." Urban Policy and Research 32 (2): 121-143. doi:10.1080/08111146.2013.877389.

Newton, P., S. Murray, R. Wakefield, C. Murphy, L.-A. Khor, and T. Morgan. 2011. Towards a New Development Model for Housing Regeneration in Greyfield Residential Precincts. Monash: Australian Housing and Urban Research Institute.

OECD. 2012. Compact City Policies: A Comparative Assessment. OECD Green Growth Studies.

Opticos. 2018. "Missing Middle." Accessed July 18. http://missingmiddlehousing.com/

Randolph, B. 2006. Delivering the Compact City in Australia: Current Trends and Future Implications. Sydney: City Futures Research Centre.

Renouf, M., S. Kenway, N. Bertram, G. London, T. Todorovic, O. Sainsbury, K. Nice, M. Moravej, and B. Sochacka. 2020. Water Sensitive Outcomes for Infill Development: Infill Performance Evaluation Framework. Monash: Cooperative Research Centre for Water Sensitive Cities.

Rowley, S., and P. Phibbs. 2012. Delivering Diverse and Affordable Housing on Infill Development Sites. Melbourne: Australian Housing and Urban Research Institute.

Sarkissian, W. 2013. "Wendy Sarkissian on NIMBYism, Community Resistance and Housing Density." The Fifth Estate. Accessed December 17. http://www.thefifthestate.com.au/spinifex/nimbyismcommunity-resistance-and-housing-density/45397

Scott, A. J., and S. T. Roweis. 1977. "Urban Planning in Theory and Practice: A Reappraisal." Environment and Planning A 9 (10): 1097-1119. doi:10.1068/a091097.

Searle, G. 2004. "The Limits to Urban Consolidation." Australian Planner 41 (1): 6. doi:10.1080/ 07293682.2004 .9982332$.

Sharam, A., L. Bryant, and T. Alves. 2015. “De-risking Development of Medium Density Housing to Improve Housing Affordability and Boost Supply." Australian Planner 52 (3): 210-218. doi:10.1080/ 07293682.2015.1034146.

Siedentop, S., S. Fina, and A. Krehl. 2016. "Greenbelts in Germany's Regional Plans-An Effective Growth Management Policy?" Landscape and Urban Planning 145: 71-82. doi:10.1016/j. landurbplan.2015.09.002.

Spira, H. 2013. "Barriers to Development in Green Square Town Centre." Planning Institute of Australia National Congress, Canberra.

United Nations. 2017. The Sustainable Development Goals Report 2017. New York: United Nations. 
United Nations General Assembly. 2016. Draft Outcome Document of the United Nations Conference on Housing and Sustainable Urban Development (Habitat III). Document A/CONF.

Urban Development Institute of Australia. 2011. "National Urban Policy." Canberra, March 1.

West Australian Planning Commission, and Department of Planning. 2015. R-Codes Amendments 2015. Department of Planning.

Wheeler, S. 2001. "Infill Development in the San Fransisco Bay Area: Current Obstacles and Responses." Annual Conference of the Association of Collegiate Schools of Planning, Cleveland.

Wiktorowicz, J., T. Babaeff, J. Breadsell, J. Byrne, J. Eggleston, and P. Newman. 2018. "WGV: An Australian Urban Precinct Case Study to Demonstrate the 1.5 C Agenda Including Multiple SDGs." Urban Planning 3 (2): 64-81. doi:10.17645/up.v3i2.1245.

Willing, R., and D. Pojani. 2017. "Is the Suburban Dream Still Alive in Australia? Evidence from Brisbane." Australian Planner 54 (2): 67-79. doi:10.1080/07293682.2017.1296875. 